\title{
T3266G AND A1112G POLYMORPHISMS IN THE LEPTIN GENE OF VARIOUS PIG BREEDS OF THE BELGOROD REGION OF RUSSIA
}

\author{
Eduard A. Snegin ${ }^{1 *}$, Anton A. Sychev ${ }^{1}$, Olesia Yu. Artemchuk ${ }^{1}$, Anatolii S. Barkhatov ${ }^{1}$, \\ Sergei R. Yusupov ${ }^{1}$, Elena A. Snegina ${ }^{1}$, Aleksandra Yu. Tishchenko ${ }^{1}$ \\ I*Belgorod State University, 85, Pobedy St., Belgorod, 308015, Russia; \\ *Corresponding Author Eduard A. Snegin, e-mail: snegin@ bsu.edu.ru;
}

Received August 2021; Accepted September 2021; Published October 2021;

DOI: https://doi.org/10.31407/ijees11.441

\begin{abstract}
USING the PCR-RFLP method, pigs were genotyped for the leptin gene (the mutations T3266G and A1112G). The boars of four breeds (Duroc, Large White, Landrace and Yorkshire) from the Belgorod region of Russia were studied in the work. The LEP gene of pigs is located in the 18-th chromosome and serves as a promising candidate gene for pig growth and obesity evaluation. Purpose of the study: Evaluation of allele frequencies for the polymorphisms A1112G and T3266G among the boars of the Duroc, Large White, Landrace and Yorkshire breeds at the farms of the Belgorod region (Russia). Materials and methods: Genomic DNA was isolated from alcoholized earmarks using the DNA-Extran-2 reagent kit (SINTOL, Russia) according to the protocol. Pigs were genotyped by PCR-RFLP. PCR products were hydrolyzed with 4 units of restriction enzyme FokI or TaqI (SibEnzyme, Russia) for 16 hours. Gel blocks were stained with ethidium bromide $(0.5 \mu \mathrm{g} / \mathrm{ml})$ and visualized on UV transilluminator to detect DNA fragments. The sequencing reaction was performed using the BigDye v. $3.1 \mathrm{Cycle}$ Sequencing Kit. DNA sequencing was performed on the ABI 3500 genetic analyzer (Applied Biosystems, USA). Result: For both polymorphisms in all breeds of pigs they revealed a higher frequency of mutant alleles recorded in Yorkshires, as well as homozygous genotypes for them. At the same time, they showed a high degree of alleles and genotype frequencies dependence for two polymorphisms caused by linked inheritance. The allele frequencies of the studied breeds for the A1112G polymorphism correspond to the data of European selection. For T3266G polymorphism the Durocs revealed a significant deviation of genotype frequencies from the Hardy-Weinberg equilibrium, which may indicate an active breeding process in this breed. In addition to the studied polymorphisms relative to the reference sequence of the chromosome 18 (NC_010460.4), we identified 11 other mutations, including 8 SNPs and 3 deletions. Of these, 10 mutations were previously described during sequencing of the leptin gene (the sequences U66254.1 and AJ865080.1). For the first time, we described the G3297A mutation in the leptin gene intron among Duroc pigs, which can potentially act as a genetic marker of lipid metabolism and fat content in pigs. Conclusion: Based on the results of the pig LEP gene fragment sequencing, they confirmed the presence of polymorphisms T3266G and A1112G relative to the reference sequence U66254.1. They revealed a higher frequency of mutant alleles recorded in Yorkshires, as well as homozygous genotypes for both polymorphisms in all breeds of pigs. At the same time, they showed a high degree of dependence of alleles and genotype frequencies for two polymorphisms caused by linked inheritance. According to the T3266G polymorphism, a significant deviation of the genotype frequencies from the Hardy-Weinberg equilibrium was revealed among the Durocs, which may be the consequence of an active selection process in this breed. The Duroc breed showed a new SNP in the leptin gene G3297A.
\end{abstract}

Key words: pigs, leptin gene, T3266G, A1112G polymorphisms, PCR-RFLP 